\title{
Mechanical allodynia triggered by cold exposure in mice with the Scn11a p.R222S mutation: a novel model of drug therapy for neuropathic pain related to $\mathrm{Na}_{v} 1.9$
}

\author{
Yosuke Matsubara ${ }^{1,2} \cdot$ Hiroko Okuda ${ }^{3} \cdot$ Kouji H. Harada ${ }^{3} \cdot$ Shohab Youssefian ${ }^{2}$ - Akio Koizumi ${ }^{3,4}$ \\ Received: 18 May 2020 / Accepted: 15 September 2020 / Published online: 24 September 2020 \\ (C) The Author(s) 2020
}

\begin{abstract}
Mutations within the SCN11A gene which encodes the voltage-gated sodium channel $\mathrm{Na}_{\mathrm{V}} 1.9$ mainly expressed in small fiber sensory neurons have been associated with neuropathic disorders; however, suitable medications have not been fully investigated. To develop drug therapies against $\mathrm{Na}_{\mathrm{V}} 1$.9-related neuropathic pain, we aimed to establish a novel model using mice carrying the Scn11a p.R222S mutation initially identified in patients with familial episodic limb pain that is characterized by paroxysmal pain induced by fatigue or bad weather conditions. We investigated the influence of cold exposure $\left(4{ }^{\circ} \mathrm{C}\right.$, overnight $)$ on the behavioral and biochemical phenotypes of Scn11 a p.R222S mutant (R222S) and wild type C57BL/6N (WT) mice. We also tested the effects of acetaminophen $(125,250 \mathrm{mg} / \mathrm{kg}$, perorally, p.o.) and traditional Japanese medicine, goshajinkigan $(0.5 \mathrm{or} 1.0 \mathrm{~g} / \mathrm{kg}$, p.o.), which are analgesic drugs prescribed to patients with neuropathic pain, in this model of cold-induced mechanical allodynia in R222S mice.

Cold-exposed R222S mice exhibited enhanced mechanical allodynia and thermal hypersensitivity compared with WT mice. The decrease of the mechanical withdrawal threshold in R222S mice was reversible $24 \mathrm{~h}$ after housing at room temperature. There was no significant change in the levels of interleukin- $1 \beta$, interleukin- 6 , tumor necrosis factor- $\alpha$, or interferon- $\gamma$ in the plasma or spinal cords of WT and R222S mice after cold exposure. Both acetaminophen $(250 \mathrm{mg} / \mathrm{kg})$ and goshajinkigan $(1.0 \mathrm{~g} / \mathrm{kg})$ significantly attenuated mechanical allodynia in R222S mice. The model of cold-induced mechanical allodynia in mice with the Scn1la p.R222S mutation is novel and useful for evaluating analgesic drugs for intractable neuropathies related to $\mathrm{Na}_{\mathrm{V}} 1.9$.
\end{abstract}

Keywords $\mathrm{Na}_{\mathrm{V}} 1.9 \cdot$ Familial episodic limb pain $\cdot$ Neuropathic pain $\cdot$ Acetaminophen $\cdot$ Goshajinkigan $\cdot$ Kampo

Electronic supplementary material The online version of this article (https://doi.org/10.1007/s00210-020-01978-z) contains supplementary material, which is available to authorized users.

Yosuke Matsubara

matsubara_yousuke@mail.tsumura.co.jp

1 Tsumura Kampo Research Laboratories, Tsumura \& Co., Ibaraki, Japan

2 Laboratory of Molecular Biosciences, Graduate School of Medicine, Kyoto University, Kyoto, Japan

3 Department of Health and Environmental Sciences, Graduate School of Medicine, Kyoto University, Kyoto, Japan

4 Social Health Medicine Welfare Laboratory, Public Interest Incorporated Association Kyoto Hokenkai, Kyoto, Japan

\section{Introduction}

Voltage-gated sodium channels $\left(\mathrm{Na}_{\mathrm{V}} \mathrm{s}\right)$ are a family of sodium ion channel proteins that play a crucial role in the electrical excitability of nerve systems and cardiac and skeletal muscles. $\mathrm{Na}_{\mathrm{V}} 1.9$, a tetrodotoxin-resistant subtype of $\mathrm{Na}_{\mathrm{V}}$ encoded by the SCN11A gene, is mainly expressed in sensory neurons. $\mathrm{Na}_{\mathrm{V}} 1.9$ exhibits slow activation kinetics and plays a role in setting activation thresholds and membrane potentials (Wood et al. 2004; Bennett et al. 2019). Several recent studies have revealed that SCN11A mutations are associated with gain-offunction $\mathrm{Na}_{\mathrm{V}} 1.9$ phenotypes and are related to peripheral paresthesia, such as painless disorders (Leipold et al. 2013; Woods et al. 2015; Phatarakijnirund et al. 2016; King et al. 2017), painful small fiber neuropathies (Huang et al. 2014; Kleggetveit et al. 2016; Han et al. 2017), and familial episodic pain syndromes, including familial episodic limb pain that is clinically indicated as paroxysmal limb pain induced by fatigue, bad weather, or cold temperature during infancy to 
adolescence (Zhang et al. 2013; Leipold et al. 2015; Okuda et al. 2016; Kabata et al. 2018).

Previous studies have also described medications for painful disorders related to $S C N 11 A$ mutations. Although lamotrigine alleviated the pain of patients carrying the SCN11A p.R222H mutation in one study (Han et al. 2017), it was ineffective against the pain of a patient with the same p.R222H mutation in another study (Tanaka et al. 2019). Gabapentin, a voltagegated calcium channel blocker, frequently used for the treatment of neuropathy, failed to control the nociceptive pain of patients with the SCN11A p.R225C mutation (Castoro et al. 2018). Acetaminophen (AcAP) and cyclooxygenase-2 inhibitors, common analgesic agents, are often prescribed for patients with familial episodic pain syndromes (Okuda et al. 2016; Kabata et al. 2018), yet they were also unable to alleviate the pain symptoms. In Japan, goshajinkigan (GJG), a traditional Japanese medicine (Kampo), is prescribed to relieve low back pain, numbness, dysuria, pollakisuria, itch, blurred vision, and neuropathies (Tawata et al. 1994; Cascella and Muzio 2017). Several studies have revealed that GJG can improve neuropathic pain via multiple mechanisms, including the spinal activation of the kappa-opioid system (Suzuki et al. 1999a; Bahar et al. 2013; Higuchi et al. 2015). It is anticipated that potential candidates, including GJG, will be efficacious against $\mathrm{Na}_{\mathrm{V}} 1.9$-related painful disorders. However, due to the lack of appropriate in vivo models of the neuropathic disorders related to SCN11A mutations, it has not been possible to appropriately evaluate the efficacy of any candidate drug.

To develop effective drug therapies for painful disorders related to SCN11A mutations, in vivo evaluation is imperative. We previously reported that knock-in mice carrying the $S c n 11$ a gene R222S missense mutation, identical to mutations found in familial episodic limb pain patients, exhibited hyperexcitability of dorsal root ganglion (DRG) neurons compared with wild type (WT) mice. In addition, Scn1 la p.R222S knock-in heterozygotes housed at normal temperature $\left(23 \pm 2{ }^{\circ} \mathrm{C}\right)$ tend to exhibit hypersensitivities to mechanical and thermal stimuli (Okuda et al. 2016). These Scn11a p.R222S mutant mice were expected to display pain behavior similar to familial episodic limb pain, such as cold-triggered pain. In this present study, we therefore first assessed the influence of cold exposure on the behavioral and biochemical properties of R222S mice to establish a novel in vivo model for $\mathrm{Na}_{\mathrm{V}} 1.9$ mutations and then attempted to detect the analgesic effects of GJG and AcAP on the cold-triggered pain behavior of the R222S mice.

\section{Materials and methods}

\section{Animals}

Animal experiment protocols were reviewed and approved by the Animal Care, Use and Ethics Committee at Kyoto
University (approval no. MedKyo18523, March 8, 2018). We used 154 healthy 6-7-week-old male C57BL/6N WT mice (purchased from Japan SLC, Inc., Shizuoka, Japan) and Scn11a p.R222S knock-in heterozygote mice. Mice weighing 19-26 g were housed in plastic cages with ad libitum food and water under controlled temperature (24 \pm $\left.2{ }^{\circ} \mathrm{C}\right)$ and humidity $(50 \pm 10 \%)$ and a 14 -h light/10-h dark cycle (lights on 07:00-21:00) prior to the start of experiments, according to the Animal Welfare Guidelines of Kyoto University. Scn11 a p.R222S knock-in heterozygote mice used in experiments were the first litters obtained by interbreeding of male Scn11a p.R222S homozygote mice (generated in the previous study (Okuda et al. 2016)) and female C57BL/6N WT mice (Japan SLC). Male WT mice were used in experiments as negative control animals. At the end of experiments, mice were euthanized by isoflurane anesthesia following cervical dislocation or exsanguination.

\section{Cold exposure}

Mice were housed in plastic cages with ad libitum food and water, and kept in a section of the refrigerator at $4 \pm 2{ }^{\circ} \mathrm{C}$ for 14-15 h (overnight). All mice used in the behavioral experiments were then placed in the experimental room $\left(20-23^{\circ} \mathrm{C}\right)$ for at least $30 \mathrm{~min}$ for adaptation.

\section{Mechanical nociceptive test (von Frey filament test)}

In the mechanical nociceptive test, mice were genotypically divided into two groups $(n=10)$ : (1) WT group and (2) R222S group. The 50\% mechanical threshold was determined using the von Frey filament test (Chaplan et al. 1994), using nine von Frey filaments with logarithmically incremental stiffness (0.008, 0.02, 0.04, 0.07, 0.16, 0.4, 0.6, 1.0, and $1.4 \mathrm{~g})$. Each mouse was placed on a stainless-steel mesh floor covered with a plexiglass cage. The filament was pressed perpendicular to the plantar surface of the right hind paw to invoke a withdrawal response (biting, licking, lifting, or shaking). The baseline of 50\% mechanical threshold was defined from mice at room temperature $\left(20-23{ }^{\circ} \mathrm{C}\right)$. Subsequently, $50 \%$ mechanical thresholds were assessed at $0.5,1,1.5,2,3,6$, and $24 \mathrm{~h}$ after termination of cold exposure.

\section{Thermal nociceptive test (tail-flick test)}

In the thermal nociceptive test, mice were genotypically divided into two group $(n=7)$ : (1) WT group and (2) R222S group. Withdrawal latencies against thermal stimuli were measured using the tail-flick test with minor modifications (Garcia-Martinez et al. 2002; Tseng et al. 2011). Here, the light beam was focused $1-1.5 \mathrm{~cm}$ from the tail tip until flicking by using a tail-flick analgesiometer (Type7350, Ugo-Basile, Comerio, Italy). The intensity of the light beam 
was adjusted to a baseline level of between 3 and $5 \mathrm{~s}$, which was defined from WT mice under room temperature (20$23{ }^{\circ} \mathrm{C}$ ). The measurement for each mouse was repeated three times at intervals of $30 \mathrm{~min}$. The average value of three measurements was taken as the withdrawal latency. The withdrawal latencies of cold-exposed mice were then measured within $1.5 \mathrm{~h}$ after termination of cold exposure.

\section{Measurement of pro-inflammatory mediators}

WT and R222S mice were divided into four groups $(n=7-$ 10): (1) WT naive group, (2) WT cold-exposed group, (3) R222S naive group, and (4) R222S cold-exposed group. In brief, mice were exposed to a cold atmosphere $\left(4 \pm 2{ }^{\circ} \mathrm{C}\right.$, overnight) and then euthanized under isoflurane anesthesia. Their blood and spinal cords were sampled within $2 \mathrm{~h}$ after cold exposure. Mice without cold exposure (naive mice; as a negative control) were also sacrificed and sampled as described above. Spinal cords were homogenized in RIPA buffer with a protease inhibitor cocktail and left for $30 \mathrm{~min}$ on ice, followed by centrifugation at $2000 \times \mathrm{g}$ for $30 \mathrm{~min}$. Whole-blood samples, obtained with a heparinized syringe, were transferred to a $1.5-\mathrm{mL}$ tube and centrifuged immediately at $1700 \times \mathrm{g}$ for $20 \mathrm{~min}$. The separated supernatants and plasma samples were stored at $-80{ }^{\circ} \mathrm{C}$ prior to measurements. The levels of proinflammatory mediators, interleukin (IL)- $1 \beta$, IL-6, tumor necrosis factor (TNF)- $\alpha$, and interferon- $\gamma$, were measured using a cytokine assay system (Bio-Plex suspension Array System, Bio-Rad Laboratories) with the MILLIPLEX MAP Mouse Cytokine/Chemokine Magnetic Bead Panel - Immunology Multiplex Assay (Millipore), according to the manufacturer's instructions.

\section{Measurement of the hind paw thickness}

WT mice $(n=8)$ and R222S mice $(n=7)$ were anesthetized with isoflurane, and the thickness ( $\mathrm{mm}$, using digital micrometer calipers) of their right hind paw was measured at room temperature $\left(20-23{ }^{\circ} \mathrm{C}\right)$. Subsequently, the right paw thicknesses of anesthetized mice were assessed within $2 \mathrm{~h}$ after termination of cold exposure.

\section{Treatments of analgesics}

We subsequently examined whether mechanical allodynia in R222S mice could be a usable model to detect the antinociceptive effect of analgesics. AcAP was purchased from Nacalai Tesque Inc. (Kyoto, Japan). GJG was provided by Tsumura \& Co. (Tokyo, Japan) as a spray-dried powder from a hot water extract of ten crude drugs in fixed proportions: Rehmanniae radix (5.0 g), Achyranthis radix (3.0 g), Corni fructus $(3.0 \mathrm{~g})$, Moutan cortex $(3.0 \mathrm{~g})$, Alismatis rhizoma (3.0 g), Dioscoreae rhizoma (3.0 g), Plantaginis semen (3.0 g), Poria (3.0 g), processed Aconiti tuber (1.0 g), and Cinnamomi cortex $(1.0 \mathrm{~g})$. Test drugs were freshly dissolved in distilled water (DW) prior to experiments.

According to the baseline of 50\% mechanical thresholds, $\mathrm{R} 222 \mathrm{~S}$ mice were divided into different treatment groups $(n=$ 8): a vehicle group, a low-dose drug group, and a high-dose drug group. The vehicle group of WT mice $(n=11-14)$ was also set as a negative control. After cold exposure, mice were evaluated for the $50 \%$ mechanical threshold and then orally administrated DW or the drugs: AcAP (125 or $250 \mathrm{mg} / \mathrm{kg}$ ) or GJG $(0.5$ or $1.0 \mathrm{~g} / \mathrm{kg})$. The dose of AcAP and GJG used in the present study approximately paralleled the typical clinical daily dose and was converted based on the body surface area according to guidelines from the US Food and Drug Administration (available from URL https://www.fda.gov/ regulatory-information/search-fda-guidance-documents/ estimating-maximum-safe-starting-dose-initial-clinical-trialstherapeutics-adult-healthy-volunteers).

\section{Statistics}

To evaluate the efficacy of the analgesics, the area under the curve (AUC, mg*h) for mechanical thresholds $(\mathrm{mg})$ from 0 (before oral administration) to $3 \mathrm{~h}$ after administration was calculated. Data with error bars represent the means \pm standard error of the mean (SEM). Multiple comparisons were performed by using one- or two-way analyses of variance (ANOVA) with post hoc Holm-Sidak's test or Dunnett's test using the Graphpad Prism version 7 software. $p$ value $<0.05$ was considered statistically significant.

\section{Results}

\section{Mechanical allodynia and thermal hyperalgesia in R222S mice occurred after cold exposure}

To assess the mechanical/thermal withdrawal behavior in mice, we used the von Frey filament test and the tail-flick test, which are common test batteries for neuropathic pain models that can stimulate a diseased area intensively and noninvasively (Sandkuhler 2009). As shown in Fig. 1a, there was no significant difference in response to mechanical or thermal stimuli in WT mice after exposure to a cold atmosphere. The result of the von Frey filament test suggested that coldexposed R222S mice exhibited remarkable mechanical allodynia of the hind paw. This mechanical hypersensitivity of the R222S mice was significant from 0.5 to $6 \mathrm{~h}$ after cold exposure and only reversed to WT levels by $24 \mathrm{~h}$ after housing at room temperature (Fig. 2). In the tail-flick test (Fig. 1b), we found that cold-exposed R222S mice also exhibited significant thermal hypersensitivity, but it was relatively moderate compared with the change in mechanical sensitivity. We could 


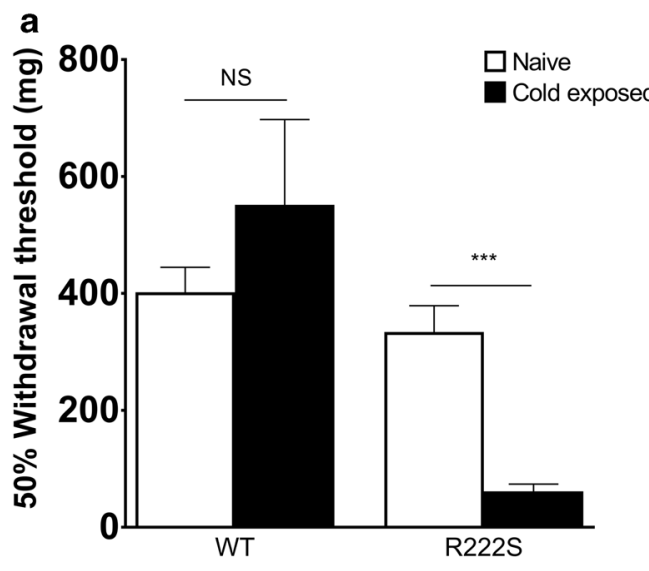

Fig. 1 Influence of cold exposure on mechanical and thermal sensitivity in wild type and Scn11a p.R222S mutant mice. a The 50\% mechanical withdrawal threshold (mg) in wild type (WT, $n=10)$ mice and Scn11a p.R222S mutant (R222S, $n=10)$ mice. b The thermal withdrawal latency (seconds) in WT $(n=7)$ mice and R222S $(n=7)$ mice. WT and R222S mutant mice were exposed to cold $\left(4{ }^{\circ} \mathrm{C}\right.$, overnight), and the mechanical/

not observe other behavioral changes, such as locomotor activity or diarrhea, in mice after cold exposure.

\section{No significant changes in biochemical or structural parameters in WT and R222S mice during cold exposure}

To assess the involvement of inflammatory signals in the behavioral changes of R222S mice during cold exposure, we analyzed the changes in pro-inflammatory mediators in the plasma and spinal cords of the test mice (Fig. 3). Compared with the naive mice, the levels of IL- $1 \beta$, IL- 6 , and TNF- $\alpha$ did

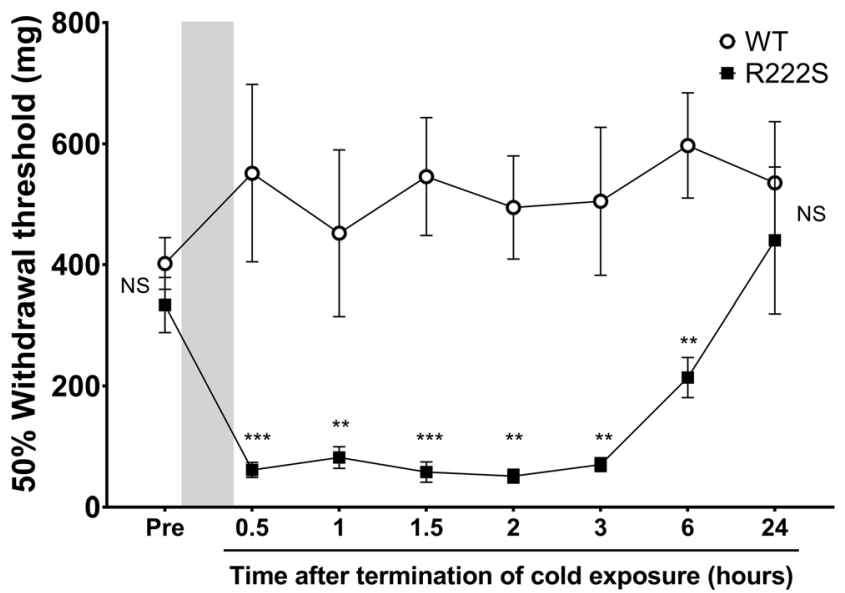

Fig. 2 Time course of the 50\% mechanical withdrawal threshold in coldtriggered wild type and Scn11a p.R222S mutant mice. Wild type (WT, $n=10)$ and Scn11a p.R222S mutant (R222S, $n=10)$ mice were exposed to cold $\left(4{ }^{\circ} \mathrm{C}\right.$, overnight), as shown by the gray zone. The $50 \%$ mechanical withdrawal threshold was evaluated at $0.5,1,1.5,2,3,6$, and $24 \mathrm{~h}$ after termination of cold exposure. Data are presented as the mean \pm SEM. One-way or two-way ANOVA followed by Holm-Sidak's multiple comparison test was performed to compare WT vs R222S mice at each time point. $* * p<0.01, * * * p<0.001$. NS, not significant

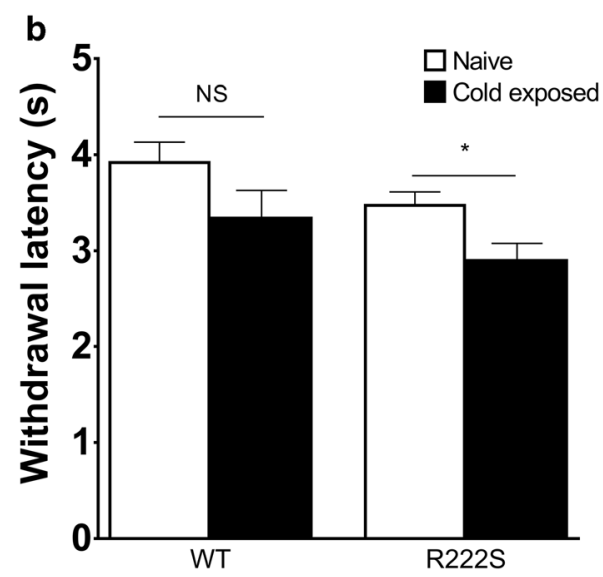

thermal sensitivities within $1.5 \mathrm{~h}$ were measured. Naive, mice housed in room temperature $\left(20-23{ }^{\circ} \mathrm{C}\right)$; Cold exposed, mice after cold exposure ( $4{ }^{\circ} \mathrm{C}$, overnight). Data are presented as the mean \pm SEM. Statistical significance was calculated using Welch's $t$ test. ${ }^{*} p<0.05$, $* * * p<0.001$. NS, not significant

not significantly differ between WT and R222S mice in response to cold exposure. We also measured the levels of interferon- $\gamma$, but these were undetectable in both the plasma and spinal cord samples. We subsequently measured the hind paw thickness of WT and R222S mice to examine whether cold exposure induced peripheral edema. However, as shown in Table 1, there were no significant differences between the mice.

\section{GJG and AcAP significantly attenuated mechanical allodynia in R222S mice}

Finally, we evaluated the antinociceptive effects of GJG and AcAP in the model of cold-triggered mechanical allodynia, using orally administered DW as vehicle control. As shown in Fig. 4, the mechanical thresholds of WT mice treated with cold exposure remained unchanged for $3 \mathrm{~h}$ after DW administration. In contrast, R222S mice given DW (R222S-DW control) clearly displayed cold-triggered mechanical allodynia. The administration of high-dose AcAP $(250 \mathrm{mg} / \mathrm{kg})$

Table 1 Changes in hind paw thickness in wild type and SCN11A p.R222S mice following cold exposure

\begin{tabular}{cll}
\hline & Naive & Cold exposed \\
\hline WT & $2.72 \pm 0.03 \mathrm{~mm}$ & $2.66 \pm 0.02 \mathrm{~mm}$ \\
R222S & $2.70 \pm 0.02 \mathrm{~mm}$ & $2.69 \pm 0.03 \mathrm{~mm}$ \\
\hline
\end{tabular}

No edematous changes in the hind paws of wild type (WT, $n=8$ ) and Scn11a p.R222S (R222S, $n=7$ ) mice were induced after cold exposure. Mice were anesthetized with isoflurane, and the thickness ( $\mathrm{mm}$, using digital micrometer calipers) of the right hind paw was measured. Naive, mice prior to cold exposure $\left(4{ }^{\circ} \mathrm{C}\right.$, overnight $)$; cold exposed, mice after cold exposure. Data are presented as the mean \pm SEM per group 

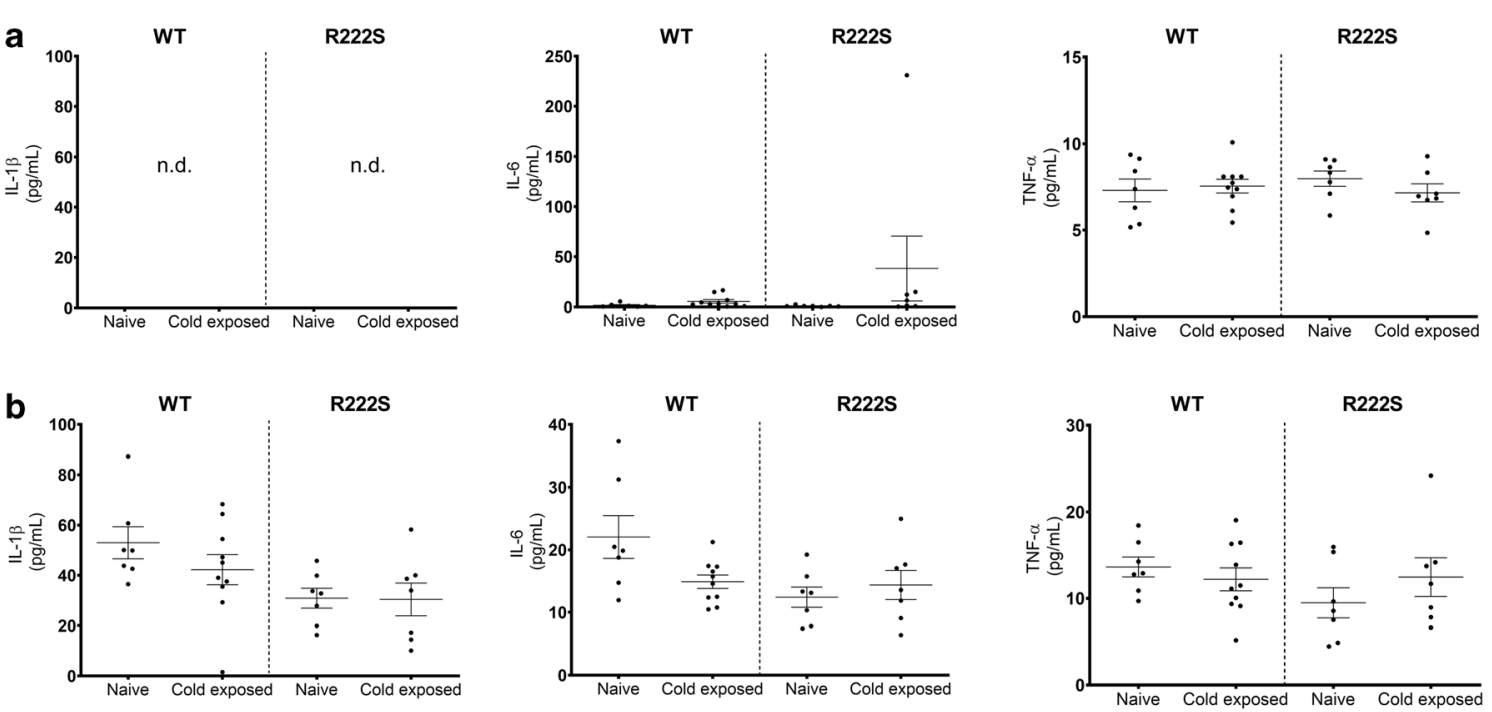

Fig. 3 Pro-inflammatory mediator levels in plasma and spinal cord samples in wild type and Scn11a p.R222S mice. The levels of proinflammatory mediators in plasma (a) and spinal cord (b) samples were determined using a cytokine assay system (Bio-Plex suspension Array System, Bio-Rad Laboratories). Wild type (WT) and Scn11a p.R222S

significantly improved mechanical allodynia of R222S mice at $0.5 \mathrm{~h}(p<0.0001)$ relative to the R222S DW control; however, its effect rapidly disappeared before $1 \mathrm{~h}$ (Fig. 4a). The administration of high-dose GJG $(1.0 \mathrm{~g} / \mathrm{kg})$ attenuated the mechanical allodynia of R222S mice at the $0.5-(p<0.001)$ and $1-(p<0.01) \mathrm{h}$ time points in comparison with the R222S DW controls, but there were no significant differences after $1 \mathrm{~h}$ of GJG administration (Fig. 4b). To assess the intensity and duration of the antinociceptive effects of GJG and AcAP, we evaluated the AUC calculated from the mechanical thresholds (mg) from 0 (before oral administration) to $3 \mathrm{~h}$ after administration. GJG, but not AcAP, significantly increased the AUC compared with the R222S DW control group (Fig. $4 a$ and $b$, respectively).

\section{Discussion}

One of the major findings of this study is that mice with the Scn11a p.R222S missense mutation exhibited mechanical allodynia and thermal hypersensitivity triggered by cold exposure (Figs. 1 and 2). These cold-evoked pain behaviors of R222S mice were similar to the clinical symptoms of patients with familial episodic limb pain. There were no significant differences in the contents of inflammatory cytokines or in the swelling of the hind paw between WT and R222S mice during cold exposure (Fig. 3 and Table 1), implying that inflammatory symptoms were not involved in the behavioral changes of R222S mice in this study.

The hyperexcitability of sensory neurons may contribute to enhanced pain transmission (Bennett et al. 2019). Our previous study showed that the firing frequency with current

mutant (R222S) mice were divided into four groups ( $n=7-10 /$ group): (1) WT naive group, (2) WT cold-exposed group, (3) R222S naive group, and (4) R222S cold-exposed group. Naive, mice housed in room temperature $\left(20-23{ }^{\circ} \mathrm{C}\right)$; Cold exposed, mice after cold exposure $\left(4{ }^{\circ} \mathrm{C}\right.$, overnight). n.d., not detected. Data are presented as the mean \pm SEM

injection in DRG neurons of R222S mice was higher than that of WT mice (Okuda et al. 2016). It is possible that the phenotypical changes in $\mathrm{Na}_{\mathrm{V}} 1.9$, resulting from the specific SCN11A missense mutation, are involved in the pathological mechanisms of hypersensitivity of the R222S mice. The level of $\mathrm{Na}_{\mathrm{V}} 1.9$ sodium current in small DRG neurons increases in the presence of inflammatory mediators (Maingret et al. 2008). In addition, posttranslational modifications of $\mathrm{Na}_{V}$ channels triggered by inflammatory mediators result in changes of firing properties in sensory neurons (Laedermann et al. 2015); however, neither biochemical nor structural evidence of inflammation was detected in this study. Cold exposure may alter other signaling events in the DRG, such as the overall profile of protein kinase, the specific upregulation of Fyn kinase that regulates $\mathrm{Na}_{\mathrm{V}} 1.7$ channels in response to repeated cold stress (Kozaki et al. 2015; Li et al. 2018), or even other posttranslational modifications, including phosphorylation, that can modify the trafficking and functions of $\mathrm{Na}_{\mathrm{V}}$ channels in neurons (Laedermann et al. 2015). As suggested by previous clinical reports, the relationship of SCN11A gene mutations and environmental changes may be involved in painful disorders (Leipold et al. 2013; Zhang et al. 2013; Huang et al. 2014; Han et al. 2015; Woods et al. 2015; Okuda et al. 2016; Han et al. 2017; King et al. 2017; Castoro et al. 2018; Kabata et al. 2018; Huang et al. 2019). Clearly, further research, for example with stable $\mathrm{Na}_{\mathrm{V}} 1$.9-expressing cell lines, is necessary to clarify the molecular mechanisms of SCN11A gain-offunction mutations.

In the present study, mechanical allodynia in R222S mice provided a sufficient window to evaluate the antinociceptive effects of drug candidates. We considered the von Frey filament test to be an appropriate means for repeated, non- 

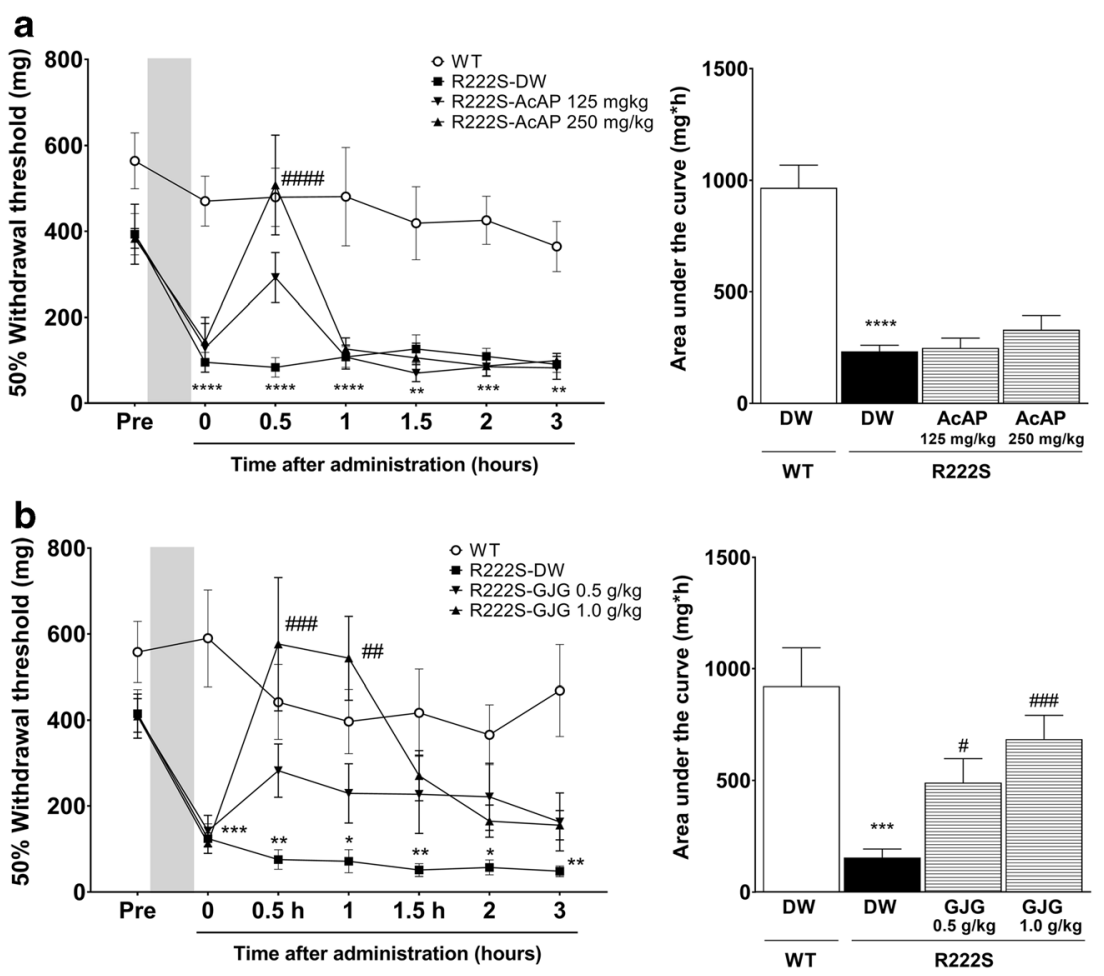

Fig. 4 Therapeutic effects of acetaminophen and goshajinkigan on the mechanical allodynia triggered by cold exposure. Wild type (WT, $n=11-$ 14) or Scn11a p.R222S mutant (R222S, $n=8$ /group) mice were orally administrated DW vehicle or drugs. a, $\mathbf{b}$ Time course of acetaminophen (AcAP) or goshajinkigan (GJG) effects on cold-triggered mechanical allodynia in R222S mice and area under the curve (AUC). Data are presented as the mean \pm SEM. Two-way ANOVA followed by Holm-

invasive measurements during short durations. The therapeutic administration of $250-\mathrm{mg} / \mathrm{kg}$ AcAP or $1.0-\mathrm{g} / \mathrm{kg}$ GJG significantly attenuated the mechanical allodynia in R222S mice after cold exposure (Fig. 4). This is thus the first report that clearly demonstrates that mechanical allodynia in R222S mice triggered by cold exposure can serve as an invaluable model to investigate therapeutic drugs for pain disorders related to the SCN11A gene mutation. The efficacy of AcAP found in the present study is in agreement with previous clinical reports (Okuda et al. 2016; Kabata et al. 2018), and a time course of its antinociceptive effects on mechanical allodynia in R222S mice (peak at $0.5 \mathrm{~h}$ after administration) is also consistent with a previous report (Mallet et al. 2008). AcAP is broadly prescribed as an antinociceptive drug for painful disorders, including familial episodic limb pain (Okuda et al. 2016; Kabata et al. 2018). The active metabolites of AcAP, Nacetyl-p-benzoquinone imine and p-benzoquinone, reduce voltage-gated calcium and sodium currents in primary sensory neurons through the activation of spinal TRPA1 (Andersson et al. 2011). In addition, AcAP and its other metabolites (paminophenol and AM404) produce the antinociceptive effect through multiple action mechanisms, including the inhibition of prostaglandin synthesis and reinforcement of the activities of the endocannabinoid system in the brain and serotonergic
Sidak's multiple comparison test was used to calculate the significance of each time course. $* p<0.05, * * p<0.01, * * * p<0.001, * * * * p<0.0001$ vs the WT DW group, ${ }^{\# \#} p<0.01,{ }^{\# \# \#} p<0.001,{ }^{\# \# \# ~} p<0.0001$ vs the R222S DW group. Statistical significance in AUC was calculated by Welch's $t$ test $* * * p<0.001, * * * * p<0.0001$ vs the WT DW group and by one-way ANOVA and post hoc Dunnett's test ${ }^{\#} p<0.05,{ }^{\# \#} p<0.001$ vs the R222S DW group

descending pain inhibitory pathway (Mallet et al. 2008; Graham et al. 2013; Jozwiak-Bebenista and Nowak 2014). Taken together, it is possible that AcAP attenuated mechanical allodynia in R222S mice through spinal and supraspinal analgesic mechanisms.

Interestingly, GJG was efficacious in the mechanical allodynia of R222S mice and may be indicative of its potential as a therapeutic candidate for $S C N 11 A$ mutation-associated neuropathies. The analgesic effect of GJG on neuropathic pain is via upregulation of the spinal $\mathrm{K}$-opioid system (Suzuki et al. 1999a; Bahar et al. 2013; Higuchi et al. 2015; Toume et al. 2019). Aconite alkaloids in GJG are immediately absorbed into the rat plasma after oral administration (Kono et al. 2015) and contribute to the antinociceptive effects by suppressing the hyperexcitability of sensory neurons via persistent depolarization (Ameri 1998; Ren et al. 2012). In Fig. 4b, GJG attenuated mechanical allodynia in R222S mice, peaking at $0.5-1 \mathrm{~h}$ after administration. The time course of GJG analgesia in the present study corresponds to the duration of the analgesic effect and the increased peripheral blood flow found in diabetes models (Suzuki et al. 1998b, 1999a, 1999b). Recent studies suggest that improvements in peripheral blood flow by vasodilators also contribute to the alleviation of neuropathic pain (Gauchan et al. 2009; Ishida et al. 2019). 
Alismatis rhizome and Dioscoreae rhizome, which are components of GJG, also contribute to improved blood flow through inhibition of platelet aggregation (Suzuki et al. 1998a). As demonstrated by previous reports (Okuda et al. 2016; Kabata et al. 2018), warming of the lesions is effective in relieving pain in patients with familial episodic limb pain. Hence, the multiple mechanisms of GJG, including improvements of peripheral blood flow that contributes to lesion warming, may be involved in the analgesic efficacy of GJG on mechanical allodynia in R222S mice.

\section{Conclusion}

This is the first report that mechanical allodynia and thermal hypersensitivity in mice carrying the Scn11a p.R222S missense mutation can be induced by cold exposure. Furthermore, the analgesic drugs, AcAP and GJG, were found to improve mechanical allodynia in R222S mice. We conclude that mechanical allodynia induced in R222S mice is suitable for evaluating the antinociceptive effects of these two drugs and that this novel pain model will be an invaluable tool for drug therapy research that targets SCN11A-related painful symptoms.

Acknowledgments We sincerely thank Dr. Naoko Tsuchiya for the multiplex analysis and Drs. Yuji Omiya and Atsushi Kaneko for reviewing the manuscript and for their invaluable advice.

Author contributions All data in this article were generated in-house, and no paper mill was used. YM designed and performed the experiments and wrote the manuscript; HO conceived and supported the experiments and corrected the manuscript; KHH, SY, and AK supervised the study and corrected the manuscript. All authors have read and approved the manuscript.

Funding This study was supported in part by Tsumura \& Co. Dr. Shohab Youssefian received a collaborative research grant from Tsumura \& Co.

\section{Compliance with ethical standards}

Animal experiment protocols were reviwed and approved by the Animal Care, Use and Ethics Committee at Kyoto University (approval no. MedKyo18523, March 8, 2018). All animal experiments were performed according to the Animal Welfare Guidelines of Kyoto University.

Competing interests Drs. Akio Koizumi and Kouji H. Harada have a patent pending regarding SCN11A (name of patent "pain gene and its applications," Japanese Patent Application No. 2014-238250).

Open Access This article is licensed under a Creative Commons Attribution 4.0 International License, which permits use, sharing, adaptation, distribution and reproduction in any medium or format, as long as you give appropriate credit to the original author(s) and the source, provide a link to the Creative Commons licence, and indicate if changes were made. The images or other third party material in this article are included in the article's Creative Commons licence, unless indicated otherwise in a credit line to the material. If material is not included in the article's Creative Commons licence and your intended use is not permitted by statutory regulation or exceeds the permitted use, you will need to obtain permission directly from the copyright holder. To view a copy of this licence, visit http://creativecommons.org/licenses/by/4.0/.

\section{References}

Ameri A (1998) The effects of Aconitum alkaloids on the central nervous system. Prog Neurobiol 56:211-235

Andersson DA, Gentry C, Alenmyr L, Killander D, Lewis SE, Andersson A, Bucher B, Galzi JL, Sterner O, Bevan S, Hogestatt ED, Zygmunt PM (2011) TRPA1 mediates spinal antinociception induced by acetaminophen and the cannabinoid Delta(9)-tetrahydrocannabiorcol. Nat Commun 2:551

Bahar MA, Andoh T, Ogura K, Hayakawa Y, Saiki I, Kuraishi Y (2013) Herbal medicine goshajinkigan prevents paclitaxel-induced mechanical allodynia without impairing antitumor activity of paclitaxel. Evid Based Complement Alternat Med 2013:849754

Bennett DL, Clark AJ, Huang J, Waxman SG, Dib-Hajj SD (2019) The role of voltage-gated sodium channels in pain signaling. Physiol Rev 99:1079-1151

Cascella M, Muzio MR (2017) Potential application of the Kampo medicine goshajinkigan for prevention of chemotherapy-induced peripheral neuropathy. J Integr Med 15:77-87

Castoro R, Simmons M, Ravi V, Huang D, Lee C, Sergent J, Zhou L, Li J (2018) SCN11A Arg225Cys mutation causes nociceptive pain without detectable peripheral nerve pathology. Neurol Genet 4:e255

Chaplan SR, Bach FW, Pogrel JW, Chung JM, Yaksh TL (1994) Quantitative assessment of tactile allodynia in the rat paw. J Neurosci Methods 53:55-63

Garcia-Martinez C, Humet M, Planells-Cases R, Gomis A, Caprini M, Viana F, De La Pena E, Sanchez-Baeza F, Carbonell T, De Felipe C, Perez-Paya E, Belmonte C, Messeguer A, Ferrer-Montiel A (2002) Attenuation of thermal nociception and hyperalgesia by VR1 blockers. Proc Natl Acad Sci U S A 99:2374-2379

Gauchan P, Andoh T, Kato A, Sasaki A, Kuraishi Y (2009) Effects of the prostaglandin E1 analog limaprost on mechanical allodynia caused by chemotherapeutic agents in mice. J Pharmacol Sci 109:469-472

Graham GG, Davies MJ, Day RO, Mohamudally A, Scott KF (2013) The modern pharmacology of paracetamol: therapeutic actions, mechanism of action, metabolism, toxicity and recent pharmacological findings. Inflammopharmacology 21:201-232

Han C, Yang Y, de Greef BT, Hoeijmakers JG, Gerrits MM, Verhamme C, Qu J, Lauria G, Merkies IS, Faber CG, Dib-Hajj SD, Waxman SG (2015) The domain II S4-S5 linker in Nav1.9: a missense mutation enhances activation, impairs fast inactivation, and produces human painful neuropathy. NeuroMolecular Med 17:158-169

Han C, Yang Y, Te Morsche RH, Drenth JP, Politei JM, Waxman SG, Dib-Hajj SD (2017) Familial gain-of-function Nav1.9 mutation in a painful channelopathy. J Neurol Neurosurg Psychiatry 88:233-240

Higuchi H, Yamamoto S, Ushio S, Kawashiri T, Egashira N (2015) Goshajinkigan reduces bortezomib-induced mechanical allodynia in rats: possible involvement of kappa opioid receptor. J Pharmacol Sci 129:196-199

Huang J, Han C, Estacion M, Vasylyev D, Hoeijmakers JG, Gerrits MM, Tyrrell L, Lauria G, Faber CG, Dib-Hajj SD, Merkies IS, Waxman SG, Group PS (2014) Gain-of-function mutations in sodium channel $\mathrm{Na}(\mathrm{v}) 1.9$ in painful neuropathy. Brain 137:1627-1642

Huang J, Estacion M, Zhao P, Dib-Hajj FB, Schulman B, Abicht A, Kurth I, Brockmann K, Waxman SG, Dib-Hajj SD (2019) A novel gain-of-function Nav1.9 mutation in a child with episodic pain. Front Neurosci 13:918 
Ishida H, Saito SY, Horie A, Ishikawa T (2019) Alleviation of mechanical stress-induced allodynia by improving blood flow in chronic constriction injury mice. Eur J Pharmacol 849:67-74

Jozwiak-Bebenista M, Nowak JZ (2014) Paracetamol: mechanism of action, applications and safety concern. Acta Pol Pharm 71:11-23

Kabata R, Okuda H, Noguchi A, Kondo D, Fujiwara M, Hata K, Kato Y, Ishikawa K, Tanaka M, Sekine Y, Hishikawa N, Mizukami T, Ito J, Akasaka M, Sakurai K, Yoshida T, Minoura H, Hayashi T, Inoshita K, Matsuyama M, Kinjo N, Cao Y, Inoue S, Kobayashi H, Harada KH, Youssefian S, Takahashi T, Koizumi A (2018) Familial episodic limb pain in kindreds with novel Nav1.9 mutations. PLoS One 13:e0208516

King MK, Leipold E, Goehringer JM, Kurth I, Challman TD (2017) Pain insensitivity: distal S6-segment mutations in NaV1.9 emerge as critical hotspot. Neurogenetics 18:179-181

Kleggetveit IP, Schmidt R, Namer B, Salter H, Helas T, Schmelz M, Jorum E (2016) Pathological nociceptors in two patients with erythromelalgia-like symptoms and rare genetic Nav 1.9 variants. Brain Behav 6:e00528

Kono T, Suzuki Y, Mizuno K, Miyagi C, Omiya Y, Sekine H, Mizuhara Y, Miyano K, Kase Y, Uezono Y (2015) Preventive effect of oral goshajinkigan on chronic oxaliplatin-induced hypoesthesia in rats. Sci Rep 5:16078

Kozaki Y, Umetsu R, Mizukami Y, Yamamura A, Kitamori K, Tsuchikura S, Ikeda K, Yamori Y (2015) Peripheral gene expression profile of mechanical hyperalgesia induced by repeated cold stress in SHRSP5/Dmcr rats. J Physiol Sci 65:417-425

Laedermann CJ, Abriel H, Decosterd I (2015) Post-translational modifications of voltage-gated sodium channels in chronic pain syndromes. Front Pharmacol 6:263

Leipold E, Liebmann L, Korenke GC, Heinrich T, Giesselmann S, Baets J, Ebbinghaus M, Goral RO, Stodberg T, Hennings JC, Bergmann M, Altmuller J, Thiele H, Wetzel A, Nurnberg P, Timmerman V, De Jonghe P, Blum R, Schaible HG, Weis J, Heinemann SH, Hubner CA, Kurth I (2013) A de novo gain-of-function mutation in SCN11A causes loss of pain perception. Nat Genet 45:1399-1404

Leipold E, Hanson-Kahn A, Frick M, Gong P, Bernstein JA, Voigt M, Katona I, Oliver Goral R, Altmuller J, Nurnberg P, Weis J, Hubner CA, Heinemann SH, Kurth I (2015) Cold-aggravated pain in humans caused by a hyperactive NaV1.9 channel mutant. Nat Commun 6:10049

Li Y, Zhu T, Yang H, Dib-Haij SD, Waxman SG, Yu Y, Xu TL, Cheng X (2018) Nav1.7 is phosphorylated by Fyn tyrosine kinase which modulates channel expression and gating in a cell type-dependent manner. Mol Pain 14:1744806918782229

Maingret F, Coste B, Padilla F, Clerc N, Crest M, Korogod SM, Delmas P (2008) Inflammatory mediators increase Nav1.9 current and excitability in nociceptors through a coincident detection mechanism. J Genet Physiol 131:211-225

Mallet C, Daulhac L, Bonnefont J, Ledent C, Etienne M, Chapuy E, Libert F, Eschalier A (2008) Endocannabinoid and serotonergic systems are needed for acetaminophen-induced analgesia. Pain 139: 190-200

Okuda H, Noguchi A, Kobayashi H, Kondo D, Harada KH, Youssefian S, Shioi H, Kabata R, Domon Y, Kubota K, Kitano Y, Takayama Y, Hitomi T, Ohno K, Saito Y, Asano T, Tominaga M, Takahashi T, Koizumi A (2016) Infantile pain episodes associated with novel
Nav1.9 mutations in familial episodic pain syndrome in Japanese families. PLoS One 11:e0154827

Phatarakijnirund V, Mumm S, McAlister WH, Novack DV, Wenkert D, Clements KL, Whyte MP (2016) Congenital insensitivity to pain: fracturing without apparent skeletal pathobiology caused by an autosomal dominant, second mutation in SCN11A encoding voltagegated sodium channel 1.9. Bone 84:289-298

Ren W, Yuan L, Li J, Huang XJ, Chen S, Zou DJ, Liu X, Yang XZ (2012) Ethanolic extract of Aconiti Brachypodi radix attenuates nociceptive pain probably via inhibition of voltage-dependent $\mathrm{Na}(+)$ channel. Afr J Tradit Complement Altern Med 9:574-583

Sandkuhler J (2009) Models and mechanisms of hyperalgesia and allodynia. Physiol Rev 89:707-758

Suzuki Y, Goto K, Ishige A, Komatsu Y, Kamei J (1998a) Effect of Gosha-jinki-gan, a Kampo medicine, on enhanced platelet aggregation in streptozotocin-induced diabetic rats. Jpn J Pharmacol 78:8791

Suzuki Y, Goto K, Ishige A, Komatsu Y, Kamei J (1998b) Effects of gosha-jinki-gan, a kampo medicine, on peripheral tissue blood flow in streptozotocin-induced diabetic rats. Methods Find Exp Clin Pharmacol 20:321-328

Suzuki Y, Goto K, Ishige A, Komatsu Y, Kamei J (1999a) Antinociceptive effect of Gosha-jinki-gan, a Kampo medicine, in streptozotocin-induced diabetic mice. Jpn J Pharmacol 79:169-175

Suzuki Y, Goto K, Ishige A, Komatsu Y, Kamei J (1999b) Antinociceptive mechanism of Gosha-jinki-gan in streptozotocininduced diabetic animals: role of nitric oxide in the periphery. Jpn J Pharmacol 79:387-391

Tanaka F, Goto T, Ogawa E, Moriyama S, Ito A, Kurosawa K, Kosaki K (2019) A case of familial episodic pain syndrome with scn11a mutation treated prophylactically with sodium channel blockers. No to Hattatsu 51:266-270

Tawata M, Kurihara A, Nitta K, Iwase E, Gan N, Onaya T (1994) The effects of goshajinkigan, a herbal medicine, on subjective symptoms and vibratory threshold in patients with diabetic neuropathy. Diabetes Res Clin Pract 26:121-128

Toume K, Hou Z, Yu H, Kato M, Maesaka M, Bai Y, Hanazawa S, Ge Y, Andoh T, Komatsu K (2019) Search of anti-allodynic compounds from Plantaginis semen, a crude drug ingredient of Kampo formula "goshajinkigan". J Nat Med 73:761-768

Tseng LF, Hogan QH, Wu HE (2011) (+)-Morphine attenuates the (-)morphine-produced tail-flick inhibition via the sigma-1 receptor in the mouse spinal cord. Life Sci 89:875-877

Wood JN, Boorman JP, Okuse K, Baker MD (2004) Voltage-gated sodium channels and pain pathways. J Neurobiol 61:55-71

Woods CG, Babiker MO, Horrocks I, Tolmie J, Kurth I (2015) The phenotype of congenital insensitivity to pain due to the NaV1.9 variant p.L811P. Eur J Hum Genet 23:561-563

Zhang XY, Wen J, Yang W, Wang C, Gao L, Zheng LH, Wang T, Ran K, Li Y, Li X, Xu M, Luo J, Feng S, Ma X, Ma H, Chai Z, Zhou Z, Yao J, Zhang X, Liu JY (2013) Gain-of-function mutations in SCN11A cause familial episodic pain. Am J Hum Genet 93:957-966

Publisher's note Springer Nature remains neutral with regard to jurisdictional claims in published maps and institutional affiliations. 